\title{
O Programa PROAMBIENTE na Transamazônica: lições aprendidas
}

\section{The PROAMBIENTE Programme in the Transamazon highway: lessons learned}

Everaldo Nascimento de Almeida - IDESP. Mestre em Agricultura Tropical Sustentável pelo Centro Agronómico Tropical de Investigación y Enseñanza e doutor em Desenvolvimento Sustentável do Tropico Úmido, pelo Núcleo de Altos Estudos Amazônicos. E-mail: everaldo.almeida@idesp.pa.gov.br

Tereza Ferreira Ximenes - Universidade Federal do Oeste do Pará (UFOPA). Mestre em Serviço Social aplicado na Pontifícia Universidade Católica de São Paulo, doutorado em Sociologia na Fundação Escola de Sociologia e Política de São Paulo e pós-doutorado na Universidade de Missouri - Columbia. E-mail: tereza.ximenes@ ufopa.edu.br

Silvio Brienæa Junior - EMBRAPA. Mestre em Solos e Nutrição de Plantas pela Universidade Federal de Viçosa (UFV) e doutor em Agricultura Tropical pela George August University of Goettingen, Alemanha. É professor dos cursos de doutorado em Ciências Agrárias da Universidade Federal Rural da Amazônia (UFRA), e de mestrado em Ciências Ambientais da Universidade Federal do Pará (UFPA). E-mail: brienza@cpatu.embrapa.br

Yared Jorge - UFRA. Mestre em Ciências Florestais pela Universidade de São Paulo e doutorado em Ciência Florestal pela Universidade Federal de Viçosa. Atualmente é professor do Curso de Doutorado em Ciências Agrárias, na Universidade Federal Rural da Amazônia. E-mail: jagyared@gmail.com

Raquel Rodrigues da Poça - EMBRAPA. Mestre em Agricultura Familiar e Desenvolvimento sustentável pelo Núcleo de Estudos Integrados sobre Agricultura Familiar (NEAF/UFPA). Email: raquel@cpatu.embrapa.br

\section{Resumo}

O objetivo desse artigo é apontar e discutir algumas lições deixadas pelo PROAMBIENTE, programa federal de apoio ao fortalecimento da agricultura familiar na Amazônia brasileira. O local de realização da pesquisa foi o polo Transamazônica, localizado na região de integração do Xingu, estado do Pará. Através de entrevistas aplicadas aos agricultores familiares, assim como a atores institucionais que participaram do período em que o programa esteve na região (2002-2006), chegou-se a um conjunto de lições que devem ser consideradas para o êxito de programas que visem o desenvolvimento rural. São elas: i. Necessidade de seleção de agricultores com real interesse e capacidade de assumir riscos; ii. Eliminação da cultura assistencialista; iii. Prioridade de atividades chaves: o caso do pagamento por serviços ambientais; iv. Utilização de uma nova abordagem do sistema produtivo; v. Assistência técnica e extensão rural com enfoque inovador; vi. Fortalecimento das organizações rurais locais; vii. Investimento na verticalização da produção; viii. $\mathrm{O}$ cuidado na geração de expectativas.

\section{Palavras-chave}

PROAMBIENTE. Lições aprendidas. Agricultura familiar

\begin{abstract}
The study aimed at formulating lessons from the Brazil's Programme for the Socio-Environmental Development of Rural Family Production (PROAMBIENTE) in the Transamazon Highway pole in the Xingu region, Para State. The methodology included interviews to small farmers as well as institutional actors that participated in the Programme. From the analysis of the Programme interventions some important lessons could be formulated, among them the need to: i) involve farmers with a real interest an capacity to assume risks; ii) avoid paternalistic behaviors (based on donations); iii) ensure continuity of key activities such as the scheme for payment for environmental services; iv) use an integrated approach of the production system; v) shift the way technical assistance and rural extension are conceived and practiced; vi) strengthen the local rural organization; vii) generate value-add to production thru processing and commercialization of products of economic importance; and viii) avoid the creation of false expectations among farmers.
\end{abstract}

\section{Keywords}

PROAMBIENTE. Lessons learned. Family agriculture. 


\section{INTRODUÇÃO}

O Programa de Desenvolvimento Socioambiental da Produção Familiar Rural (PROAMBIENTE) foi um programa piloto de políticas públicas sancionado em 2004, cujo objetivo era promover o equilíbrio entre a conservação dos recursos naturais e a produção familiar rural, por meio da gestão ambiental territorial, do planejamento integrado das unidades produtivas e da prestação de serviços ambientais (PROAMBIENTE, 2003). O PROAMBIENTE foi idealizado por representantes de movimentos sociais da Amazônia que buscavam uma nova forma de fortalecimento da agricultura familiar que levasse à consonância socioeconômica, cultural e ambiental em detrimento aos vários modelos excludentes, cujas formas de implantação perpetuavam cada vez mais o sofrimento de milhares de famílias rurais da Amazônia.

Após a atuação em onze regiões denominadas "polos" em todos os estados da Amazônia, o programa, a exemplo de inúmeras experiências realizadas por famílias rurais, estagnou em meio ao processo. Os motivos foram muitos, porém, a principal razão para o encerramento das atividades foi o cancelamento no repasse de recursos federais para a continuação das ações planejadas. Dessa forma, toda a estrutura criada para a sua concretização foi prejudicada. No entanto, no polo Transamazônica, localizado na região de integração do Xingu, estado do Pará, uma série de lições foram obtidas a partir da experiência do programa.

Nesse sentido, o presente estudo teve como objetivo registrar e analisar algumas lições deixadas pelo PROAMBIENTE durante o período em que esteve presente na região.

\section{METODOLOGIA}

A coleta de dados foi realizada entre os meses de junho a agosto de 2010. Nesse período, buscaram-se informações prévias das atividades do PROAMBIENTE na área de abrangência, somados a aplicações de entrevistas semiestruturadas a 50 famílias rurais (16\% da área amostral), assim como a atores institucionais que participaram das ações do programa durante o período em que o mesmo esteve vigente na região.

A área selecionada para o estudo foi o polo Transamaźninica, região que compreende os municípios de Anapu, Senador José Porfírio e Pacajá, selecionados previamente por representantes dos movimentos sociais rurais da região de integração do Xingu, estado do Pará.

Novos Cadernos NAEA, v. 16, n. 1, Suplemento, p. 247-260, jun. 2013 


\section{O PROAMBIENTE}

O PROAMBIENTE foi um programa piloto de políticas públicas incorporado ao Ministério do Meio Ambiente (MMA) em 2004, voltado à pequena produção rural, cujo objetivo foi promover o equilíbrio entre a conservação dos recursos naturais e a produção familiar rural, por meio da gestão ambiental territorial, do planejamento integrado das unidades produtivas e da prestação de serviços ambientais (PROAMBIENTE, 2003).

Suas atividades iniciaram em 2002, em 11 polos distribuídos em todos os estados da Amazônia Legal, denominados de polos do PROAMBIENTE. No estado do Pará, foram implantados os polos do Capim e da Transamazônica, esse último contemplou três municípios (Senador José Porfírio, Pacajá e Anapu), selecionados a partir da particularidade de cada um deles no que se refere ao tipo de produção familiar realizada.

Nopolo da Transamazônica, as primeiras ações do PROAMBIENTE iniciaram a partir de 2002, com os seminários de socialização da proposta e seguiram com reuniões, oficinas, construções dos planos de uso das propriedades, além de atividades de assistência técnica e extensão rural. O programa foi encerrado em 2006, determinado pelo cancelamento do repasse dos recursos federais que previamente assegurava a continuidade de suas ações.

\section{RESULTADOS E DISCUSSÕES}

A implantação do PROAMBIENTE no polo da Transamazônica seguiu um cronograma de atividades dividido em etapas. A primeira etapa foi realizada com os seguintes elementos: seminários de socialização, cadastramento das famílias, reuniões, oficinas, formação de grupos comunitários, intercâmbios, elaboração dos planos de desenvolvimento locais sustentáveis (PDLS) e dos diagnósticos para as unidades de produção familiar (UPF), planos de uso (PU), acordos comunitários (AC) e a realização dos serviços de assistência técnica e extensão rural (ATER).

As ações que seriam realizadas na segunda etapa, entre elas a efetivação dos PU nas propriedades rurais, foram inviabilizadas devido ao cancelamento do repasse dos recursos governamentais para a continuidade do programa no polo. Entretanto, as experiências vividas pelas famílias rurais, assim como de outros atores que participaram do PROAMBIENTE na região proporcionaram a elaboração de um conjunto de importantes lições apresentadas e discutidas a seguir. 


\section{LIÇÕES APRENDIDAS}

\section{IDENTIFICAÇÃO DE AGRICULTORES COM REAL INTERESSE E CAPACIDADE DE ASSUMIR RISCOS}

O desenvolvimento local está associado, normalmente, a iniciativas inovadoras e mobilizadoras da coletividade, articulando as potencialidades locais nas condições dadas pelo contexto (HAVERI, 1996). Para promovê-lo no âmbito rural há a necessidade, entre muitas ações iniciantes, de uma sociedade muito bem organizada, um capital social fortalecido onde cada membro conheça e execute o seu papel.

As ações incentivadas por programas e projetos que visem o fortalecimento e o desenvolvimento local estão diretamente ligadas à coletividade, sem a qual, seguramente não alcançarão os êxitos desejados. Os vários estudos sobre o papel de experiências ocorrentes em toda América Latina, em especial na Amazônia brasileira, demonstram a importância da seleção de pessoas que possuem o compromisso com o desenvolvimento local, sobretudo no âmbito rural (BUNCH, 1993; SABOGAL et al., 2009).

Em muitos casos, os selecionados são as próprias lideranças locais, pessoas influentes junto às organizações rurais, ONGs ou instituições doadoras. A prática do nepotismo é frequente, assim como o favorecimento de pessoas que têm afinidades com lideranças ou que são componentes do mesmo grupo político partidário. Essas práticas, apesar de serem comuns, devem ser evitadas, uma vez que muitos selecionados não possuem nenhum compromisso coletivo, procuram vantagens individuais, dificilmente são envolvidos com atividades agrícolas e não possuem aptidão para enfrentar os desafios propostos.

A desconfiança de parte dos beneficiários, aliada a insegurança de não conseguir cumprir com as obrigações assumidas junto aos programas de desenvolvimento, muitas vezes ocasiona a desistência dos contemplados. A seleção dos atores deve ser feita com critérios. É interessante buscar agricultores que possuam aptidão para determinadas tecnologias ou que já tenham iniciativas interessantes em suas propriedades, como criação de peixes, sistemas agroflorestais, manejo de floresta, entre outras atividades produtivas sustentáveis.

\section{ELIMINAÇÃO DA CULTURA ASSISTENCIALISTA}

$\mathrm{Na}$ literatura há relatos de uma série de exemplos sobre experiências incentivadas por programas e projetos que foram totalmente abandonadas frente Novos Cadernos NAEA, v. 16, n. 1, Suplemento, p. 247-260, jun. 2013 
às primeiras dificuldades surgidas (BUNCH, 1994; ALMEIDA et al., 2006). É comum observar em muitas áreas rurais máquinas de arroz enferrujadas, casas de farinhas comunitárias que nem sequer foram montadas; caminhões parados por falta de manutenção ou mesmo sem combustível; sementes de alta qualidade que apodrecem antes de serem levadas ao semeio.

Quando o único progresso que as pessoas de uma determinada localidade observam é acompanhado de doações, elas podem passar a acreditar que não são capazes de progredir por conta própria. Nesse caso, fica a impressão de que não se pode conseguir nada se não contarem com ajuda "de fora" (BUNCH, 1994).

Nesse contexto, apesar das precauções tomadas nas discussões com as famílias participantes e, posteriormente, na implantação das práticas designadas, foi observada a estagnação de atividades extremamente necessárias para a continuidade do programa na região. O principal exemplo verificado no PROAMBIENTE foi o caso dos viveiros comunitários, que foram construídos com recursos da EMBRAPA Amazônia Oriental e apoio da equipe técnica do programa. O objetivo da construção dos viveiros era dispor mudas de espécies florestais e frutíferas para as famílias rurais. Entretanto, o cancelamento do repasse de verbas afetou diretamente a produção dos viveiros já instalados. Os prejuízos causados pela falta desse repasse incidiram na aquisição de compra de mudas e sementes que aliado ao escasso recurso humano para levar a atividade adiante ocasionou o abandono dos viveiros comunitários.

Os agricultores questionavam se o PROAMBIENTE voltaria para reativar os viveiros, sem se darem conta que a continuidade dessa atividade, em específico, dependia unicamente deles e não apenas da equipe técnica do programa ou de outro apoio externo. O que mais foi observado nas áreas visitadas foram plantios de mudas doadas pelo PROAMBIENTE ou por outro programa de fomento. A produção de mudas ficou condicionada a incentivos externos caracterizando uma relação de dependência.

O que aconteceu com os viveiros comunitários do PROAMBIENTE foi apenas mais um dos inúmeros casos desalentadores que não será levado adiante pelos agricultores, a não ser que novos projetos ou até mesmo o PROAMBIENTE, em uma nova versão, possam ressuscitá-los.

Se a adoção de alguma inovação passar a depender de doações, como foi o caso da doação de mudas e construção dos viveiros comunitários, ou se as pessoas passarem a acreditar nisso, os agricultores locais não as adotarão e deixarão de tentar ensinar essa inovação a seus vizinhos (BUNCH, 1994).

Estudos mostram que para evitar o paternalismo, a única possibilidade de ação é motivar as pessoas para que façam as coisas por si mesmas (BUNCH, 1994; 
EASTERLY, 2006). Mas como fazer essas pessoas, que tantas vezes parecem conservadoras, tradicionalistas e não inovadoras, adquirirem motivação para levar a cabo seu próprio processo de desenvolvimento? Sobre esse questionamento, Bunch (1994) explica que "a saída é fazer com que os indivíduos de alguma maneira se entusiasmem, ou seja, é o desejo ou vontade de trabalhar de modo a alcançar um objetivo. É a vontade de pisar em terra desconhecida - experimentar, estudar, tomar decisões, cooperar com os outros e trabalhar junto visando um objetivo comum".

\section{PRIORIDADES DE ATIVIDADES CHAVES - O CASO DO PAGAMENTO POR SERVIÇOS AMBIENTAIS (PSA)}

A concepção de trabalho abordada pelo PROAMBIENTE buscava minimizar as várias demandas socioambientais, econômicas e culturais da população rural dos polos selecionados. Os PDLS foram construídos para identificar essas demandas e subsidiarem ações estratégicas para o fortalecimento da agricultura familiar no polo, apoiada pelo PROAMBIENTE e pelas parcerias construídas junto à administração pública nas diferentes esferas (SOUZA, 2006).

A proposta inovadora de fazer um programa que incluía créditos diferenciados à agricultura, formação e investimentos na infraestrutura das propriedades rurais e das comunidades agradou e atraiu muitas famílias (SOUZA, 2006). No entanto, o grande interesse dos agricultores era a oportunidade da remuneração pelos serviços ambientais. Para isso, houve uma série de requisitos a serem cumpridos e mensurados nas propriedades, a partir das visitas técnicas de experts na atividade.

No PROAMBIENTE, as técnicas de cultivo e de manejo dos recursos naturais empregadas nas unidades produtivas eram determinantes para que esta viesse a ser considerada produtora de serviços ambientais (OLIVEIRA; ALTAFIN, 2008). Esses autores destacam que na medida em que atuavam na recuperação de mananciais e nascentes, na recuperação das matas ciliares, quando evitavam o uso do fogo ou empregavam técnicas alternativas no preparo de áreas, essas famílias estimulavam a interação de um conjunto de fatores essenciais no processo de provimento de serviços ambientais.

A proposta de PSA debatida pelo PROAMBIENTE foi ao encontro de atividades já realizadas pelas famílias cadastradas antes da entrada do programa no polo. A manutenção da área de reserva para uso de atividades extrativas não predatórias, a recuperação de áreas de pastos com plantios de espécies pioneiras

Novos Cadernos NAEA, v. 16, n. 1, Suplemento, p. 247-260, jun. 2013 
ou exóticas, o plantio de espécies frutíferas em áreas de mata secundária sem o uso do fogo, assim como, a preservação das matas ciliares foram algumas das atividades já desenvolvidas por agricultores da região e justificaram a efetivação do PSA.

Os treinamentos, intercâmbios e dias de campo, somados ao modelo inovador de ATER implementado pelo programa, foram ao encontro do que centenas de agricultores praticavam em matéria de manejo dos recursos naturais. Essas estratégias contribuíram para o aperfeiçoamento das técnicas produtivas por meio do aporte de novos conhecimentos, como a substituição do sistema de queimadas e o uso de técnicas com princípios agroecológicos para recuperação de áreas degradadas.

O valor pago a cada família rural pelos serviços ambientais prestados nos valores atuais era de U\$51,00/mensal. Embora estivesse muito abaixo do real valor das atividades realizadas nas propriedades rurais, a valorização desses serviços já diferenciava os participantes do PROAMBIENTE dos demais agricultores da região. Nessa ótica, por menor que fosse a remuneração dos serviços prestados, o direito de terem suas atividades valorizadas despertou o interesse de outras famílias. Por outro lado, havia um anseio em mudar a maneira tradicional de uso dos recursos, e o programa foi a oportunidade que favoreceu a mudança. Naquele momento, a adoção de novas práticas sustentáveis de uso dos recursos passava a ser uma obrigação e não mais uma oportunidade.

A remuneração dos serviços às famílias foi efetuada durante um período de apenas 06 meses e a exemplo das outras ações planejadas pelo PROAMBIENTE, também foi prejudicado com o encerramento do repasse dos recursos. Entretanto, mesmo após o cancelamento do PSA várias famílias continuaram algumas práticas com princípios de sustentabilidade (Tabela 1).

Tabela 1. Práticas ambientais adotadas (\%) pelas famílias rurais após a intervenção do PROAMBIENTE no polo transamazônica $(\mathrm{n}=50)$

\begin{tabular}{|c|c|c|}
\hline \multicolumn{2}{|c|}{ Atividades implementadas } & $\begin{array}{l}\text { Famílias que } \\
\text { adotaram (\%) }\end{array}$ \\
\hline \multicolumn{2}{|c|}{ Redução do desmatamento em áreas de floresta primária } & 95 \\
\hline \multicolumn{2}{|c|}{ Redução do desmatamento em áreas de floresta secundária } & 44 \\
\hline \multirow{2}{*}{ Redução do uso de agrotóxico } & Veneno para insetos & 26 \\
\hline & Veneno para ervas daninhas & 7 \\
\hline
\end{tabular}




\begin{tabular}{|l|l|c|}
\hline \multirow{4}{*}{ Controle e redução de queimadas } & Utilização do contra fogo & 73 \\
\cline { 2 - 3 } & Aviso aos vizinhos & 80 \\
\cline { 2 - 3 } & Horário de queimada & 77 \\
\cline { 2 - 3 } & Uso de aceiro & 88 \\
\hline Reflorestamento & 9 \\
\hline Uso de adubação orgânica & 5 \\
\hline Manejo no uso do lixo & 5 \\
\hline Melhoria no manejo da pecuária extensiva & 5 \\
\hline
\end{tabular}

\section{NOVA ABORDAGEM DO SISTEMA PRODUTIVO}

A mudança de atitude dos agricultores familiares com relação ao sistema produtivo foi um dos pontos positivos do PROAMBIENTE no polo Transamazônica. A forma de observar a propriedade sob uma ótica sistêmica fez com que algumas famílias adotassem uma abordagem integrada na gestão de suas propriedades. A busca de uma "propriedade rural ideal" passava pela adoção de um sistema de produção, no qual a família é o centro, pautado na lógica da integração.

$\mathrm{Na}$ abordagem de um sistema produtivo integrado, a produção de culturas alimentares, os quintais agroflorestais, a criação de pequenos animais e de gado convivem em perfeita harmonia com a extração de madeira, a caça, a coleta de frutas, a pesca e outras atividades extrativistas (MMA; SCA; IPAM, 2002).

Nesse contexto, a conservação dos recursos naturais é fortalecida, pois o manejo desses recursos (florestas, lagos, igarapés, animais e demais componentes) contribui diretamente para a subsistência e renda das famílias, uma vez que ao longo do ano sempre haverá um sistema produzindo. Na perspectiva ambiental, as iniciativas inseridas em sistemas de manejo integrado apresentam grande potencial de promover a manutenção e recuperação da biodiversidade, o que reduz o risco de perda ou danos às populações de animais e plantas nativas.

\section{ASSISTÊNCIA TÉCNICA E EXTENSÃO RURAL COM ENFOQUE INOVADOR}

A Política Nacional de Assistência Técnica (PNATER), criada em 2003 pelo Ministério de Desenvolvimento Agrário (MDA), tem proporcionado uma 
série de mudanças ao setor. A formação de equipes multidisciplinares, assim como a participação mais efetiva da população rural nas discussões sobre os projetos elaborados e a melhoria da infraestrutura de trabalho foram algumas das atribuições conquistadas.

Entretanto, ainda há uma forte resistência a essa nova metodologia. As ações governamentais não conseguiram eliminar antigos e novos entraves que emergem com mais intensidade à medida que a política de fortalecimento da ATER se concretiza. Sobre esse contexto, observou-se condições que necessitam ser modificadas para a adoção da política em voga. Sobre tais situações destacamse: i. agentes de extensão ainda desenvolvem suas atividades em uma visão reducionista e tecnicista; ii. diferenças internas entre os extensionistas motivados por interesses individuais e partidários; iii. dificuldades no cumprimento dos compromissos assumidos pelas instituições de ATER, face a carência na estrutura técnica e física de muitas agências locais de extensão; iv. alta rotatividade de técnicos de extensão nos escritórios municipais.

O modelo de extensão rural adotado pelo PROAMBIENTE foi implantado no mesmo período que a política governamental de ATER. Os dois modelos apresentavam semelhanças entre si, principalmente, no que se refere a uma maior abertura para a participação dos beneficiários nas tomadas de decisões e moldada a princípios agroecológicos.

A equipe de ATER do PROAMBIENTE era composta de jovens profissionais da área de ciências agrárias provindos da própria região. Também participavam da equipe, produtores inovadores que eram capacitados para atuar como agentes de extensão nas comunidades que recebiam apoio do programa. Com a orientação dessa equipe, os agricultores adotaram importantes práticas, entre as quais se destacam: manejo do uso do fogo, reduções do desmatamento e do uso de agrotóxicos. Entretanto, o longo intervalo de tempo entre as ações do PROAMBIENTE, conflitos entre a concepção de ATER entre agências de extensão oficial e do programa, além do imediatismo de resultados práticos foram as principais limitantes para o êxito do modelo de ATER na região.

\section{FORTALECIMENTO DAS ORGANIZAÇÕES RURAIS LOCAIS}

Nas muitas localidades rurais abrangidas pelo programa observaram-se organizações enfraquecidas que não conseguiam representar ou defender os interesses das famílias locais. O pouco conhecimento sobre gestão, associativismo e cooperativismo foram algumas das limitantes observadas. Tais fatores fizeram 
com que as representações comunitárias perdessem representatividade diante das populações locais que procuravam resolver as pendências relacionadas às questões rurais junto às secretarias municipais de agricultura e aos sindicatos rurais de seus municípios.

O fortalecimento das organizações locais é um processo de aprendizagem que necessita de componentes básicos para funcionar, como a confiança e a participação. Sem a confiança mútua entre os membros que compõem uma equipe de gestão e dos agricultores que a representam, dificilmente ocorre desenvolvimento no local. Muitas atividades realizadas pelos agricultores, vinculadas ou não a projetos, não surtem efeitos devido às desconfianças existentes entre os membros das localidades. A relação de confiança entre diferentes atores é um processo construído e demanda tempo.

Nas comunidades tradicionais como ribeirinhas, quilombolas, indígenas e extrativistas, nas quais os habitantes se relacionam socialmente durante décadas, a confiabilidade é mais coesa. Nas áreas de colonização, como é o caso da região da transamazônica, onde os agricultores são de procedências, culturas e pensamentos distintos, o processo de aquisição de confiança é mais lento.

A confiança está intimamente ligada a outro elemento, a participação. Uma participação efetiva da população local nas atividades realizadas, assim como nas tomadas de decisões potencializa o êxito dos programas/projetos. Entretanto, o que se observa em várias experiências em comunidades rurais na Amazônia brasileira é a convergência de poderes reduzidos a pequenos grupos. Há casos em que apenas os presidentes das organizações são responsáveis por atender a todas as demandas apresentadas pelas famílias, os demais membros não participam na divisão de tarefas, atuam apenas como figuras ilustrativas.

A integração da comunidade através da participação de seus membros é de suma importância para alimentar o processo organizativo. $\mathrm{O}$ envolvimento da população local ajuda a assegurar o respeito dos programas e projetos aos valores culturais locais e a garantir que esteja sempre orientado pelas carências e necessidades sentidas pela população (LELE, 1975). A principal razão para a participação de agricultores em programas ou projetos que visem o desenvolvimento rural local é que ela pode ser essencial para garantir a continuidade do trabalho (BUNCH, 1994). É somente com a participação efetiva dos agricultores familiares na divisão de responsabilidades, assim como nas tomadas de decisões, que seus representantes se sentem mais seguros e fortalecidos para atenderem as demandas apresentadas e buscarem benefícios em prol das comunidades a que pertencem. 


\section{INVESTIMENTO NA VERTICALIZAÇÃO DA PRODUÇÃO - O CASO DA CADEIA PRODUTIVA DO CACAU (Theobroma cacao L.)}

Com uma produção de 35,1 mil t/ano (IBGE, 2009), a lavoura cacaueira na região exerce um importante papel no âmbito da pequena produção. Em 2010, nos municípios do polo, a produção alcançou ao redor de 3.200 t (IBGE, 2012). Apesar de todo o potencial produtivo e econômico, a cadeia produtiva dessa frutífera precisa ser fortalecida. A condição em que são realizados o beneficiamento e a comercialização das amêndoas do cacau restringe a possibilidade de qualquer agregação de valor à produção.

Não existe, ou se existe apenas de forma embrionária, uma preocupação no sentido de modernizar a cadeia produtiva em um modelo mais empresarial. Sabogal et al. (2009) destacam que há a necessidade de estimular a formação de redes de produtores para atender demandas de mercado e, consequentemente, fortalecer suas organizações para o comércio. No presente caso, a criação de cooperativas agrícolas poderia ser o primeiro passo a ser dado para desencadear o processo.

As possibilidades de aplicação das ideias cooperativistas são bem amplas e certamente contribuiriam à transformação das relações de trabalho e melhoria da qualidade de vida da população. No polo em questão, o papel da cooperativa seria o de aglutinar a produção de polpa e amêndoa provindas dos sistemas produtivos, e a partir de então criar demandas aos produtos a serem comercializados.

\section{O CUIDADO NA GERAÇÃO DE EXPECTATIVAS ENTRE OS BENEFICIÁRIOS}

É muito comum exemplos de programas ou projetos que prometem benefícios caso as atividades implantadas sejam adotadas. A agregação de renda, a garantia de mercado à produção obtida, a assistência técnica permanente e de qualidade são algumas das promessas que surgem nas reuniões iniciais. Os resultados, quando não cumpridos, promovem o descrédito das instituições responsáveis pelas ações e comprometem o seguimento das atividades.

O atrelamento do PROAMBIENTE ao repasse de recursos federais era a garantia de que todas as ações previstas seriam executadas. Quando houve a interrupção do repasse, importantes ações que efetivariam a implementação do programa também foram interrompidas e, dessa forma, mais uma experiência inovadora chegou ao seu final. Apesar de todo esforço realizado pelos gestores 
do programa, através da execução de projetos para cumprir a programação, não houve como dar continuidade as ações.

Embora, a proposta do PROAMBIENTE tenha sido inovadora aos participantes, o término do projeto foi uma derrota tanto para esses beneficiários quanto para o grupo que coordenou o programa no polo. Assumir riscos é algo que se tem de levar em consideração em propostas dessa natureza, quando envolvem pessoas a responsabilidade deve ser dividida entre todos que participam do processo.

\section{CONCLUSÕES}

O PROAMBIENTE foi um programa piloto de políticas públicas criado com objetivo de promover o equilíbrio entre a conservação dos recursos naturais e a produção familiar rural. Essa experiência inovadora ocorreu em 11 polos distribuídos em toda região amazônica, no polo da Transamazônica a forte articulação entre os movimentos sociais e instituições compromissadas com o desenvolvimento rural sustentável integrou mais de 300 famílias de agricultores ao programa.

O início do PROAMBIENTE foi promissor, os vários seminários de socialização, capacitações, intercâmbios de experiências, tudo isso alicerçado a uma nova ATER moldada a princípios agroecológicos e a algumas ações inovadoras como o pagamento pelos serviços ambientais realizados nas propriedades rurais, deu confiabilidade ao programa.

Apesar dos resultados obtidos, o programa foi encerrado quatro anos após seu inicio em uma etapa de essencial importância para a consolidação de algumas das metas propostas. Entretanto, a experiência inovadora do PROAMBIENTE disponibilizou um conjunto de lições que devem ser consideradas para o êxito de programas ou projetos de desenvolvimento rural a serem implementados na Amazônia. São elas: i. Identificação de agricultores com real interesse e capacidade de assumir riscos; ii. Eliminação da cultura assistencialista; iii. Prioridade de atividades chaves; iv. Nova abordagem de sistema produtivo em pequenas propriedades rurais; v. Assistência técnica e extensão rural com enfoque inovador; vi. Fortalecimento das organizações rurais locais; vii. Verticalização da produção; viii. Cuidado na geração de expectativas.

Essas lições, em diferentes níveis, foram encontradas em muitas outras iniciativas desenvolvidas na Amazônia legal. Entretanto, foi na proposta desafiadora e inovadora do PROAMBIENTE, que atuava em todos os níveis 
que promovem o desenvolvimento rural sustentável, que essas lições foram bem mais evidentes.

\section{REFERÊNCIAS}

ALMEIDA, E. N. de; SABOGAL, C.; BRIENZA JÚNIOR, Silvio. Recuperação de áreas alteradas na Amazônia brasileira: Experiências locais, lições aprendidas e implicações para políticas públicas. Belém: CIFOR/EMBRAPA, 2006. 204p.

BUNCH, R. Duas espigas de milho: uma proposta de desenvolvimento agrícola alternativo. Tradhção: John C. Comerford. Rio de Janeiro: AS-PTA, 1994. 221p. EASTERLY, W. The white man's burden: why the west's efforts to aid the rest done so much ill and so little good. New York: The Penguin Press, 2006. 448p.

HAVERI, A. Strategy of comparative advantage in local communities. Outlasvirta, Lasse, Finnish local government in transition, v. 22, n. 4, 1996.

IBGE. Disponível em: <http://www.sidra.ibge.gov.br/bda/tabela/protabl. asp?c $=1613 \& z=t \& o=11 \& \mathrm{i}=\mathrm{P}>$. Acesso em: out. 2012.

. Produção Agrícola Municipal 2008. Rio de Janeiro: IBGE, 2009.

LELE, Uma. The design of the rural development: lessons from Africa. Washington: World Bank, 1975. 264p.

MMA; SCA; IPAM. Bases Técnicas para a Estruturação do Programa de "Recuperação de Áreas Alteradas na Amazônia”. Belém: MMA/IPAM/ SCA, 2002. 54 p.

OLIVEIRA, L. R. de; ALTAFIN, I. G. PROAMBIENTE: uma política de pagamento dos serviços ambientais no Brasil. In: CONGRESSO DA SOCIEDADE BRASILEIRA DE ECONOMIA, ADMINISTRAÇÃO E SOCIOLOGIA RURAL, 46. 2008, Rio Branco. Anais... Rio Branco: SOBER, 2008.

PROAMBIENTE. Proposta definitiva da sociedade civil organizada entregue ao Governo Federal. Brasília, 2003. 32p.

SABOGAL, C.; ALMEIDA, E.; BRIENZA JÚNIOR, S.; MEZA, A. Reabilitação de áreas degradadas nas regiões amazônicas do Brasil e do Peru: revisão de iniciativas produtivas e lições aprendidas. In: PORRO, R (Ed.). Alternativa agroflorestal na Amazônia em transformação. Belém: ICRAF; EMBRAPA, 2009. p. 349-377. 
SOUZA, Ana Paula Santos. O desenvolvimento socioambiental na

Transamazônica: a trajetória de um discurso a muitas vozes. 2006. 140f. Dissertação (Mestrado em Agriculturas Familiares e Desenvolvimento Sustentável) - Curso de Pós-Graduação em Agriculturas Amazônicas, Universidade Federal do Pará, Belém, 2006. 